\title{
ORIGINAL ARTICLE FREQUENCY OF RADIAL ARTERY OCCLUSION IN PATIENTS UNDERGOING PERCUTANEOUS CARDIAC CATHETERIZATION BY RADIAL ACCESS
}

\author{
Usman Mahmood Butt ${ }^{1}$, Muhammad Abu Bakar², Muhammad Khaleel Iqbal' ${ }^{1}$, Shahzad \\ Shoukat $^{3}$, Rao Shahzad Abdul Tawwab Khan ${ }^{4}$, Muzaffar Ali ${ }^{1}$ \\ ${ }^{1}$ Jinnah Hospital, Lahore, Pakistan, ${ }^{2}$ Faisalabad Institute of Cardiology, Faisalabad, Pakistan, ${ }^{3}$ Punjab Institute of Cardiology Lahore, \\ Pakistan, ${ }^{4}$ Wazirabad Institute of Cardiology, Wazirabad, Pakistan
}

Objectives: To assess the frequency of radial artery occlusion (RAO) in patients undergoing percutaneous cardiac catheterization.

Methodology: A descriptive cross sectional study was carried out at cardiology department Jinnah hospital, Lahore from April - October 2018. One hundred thirty one consecutive patients who had undergone percutaneous cardiac catheterization via the trans-radial approach were enrolled in the study. Post procedure patients were followed in the ward and after 24 hours, Allen's test was used for checking the patency of the radial artery. Color Doppler USG was performed in the patients with absent radial artery and RAO was confirmed. Data was entered and analysed in SPSS version 21.0.

Results: Out of 131 patients who had undergone for percutaneous cardiac catheterization $63.4 \%$ were male and $36.6 \%$ were female. Among these cases radial artery occlusion was detected in $52(39.7 \%)$ patients. No statistically significant difference was found with effect modifiers like age, gender, duration of procedure and type of intervention statistically insignificant difference was observed $(\mathrm{P}>0.05)$.

Conclusion: A considerable number of patients were observed with radial artery occlusion with trans-radial approach thought statistically insignificant difference was noted among all ages, gender or type of intervention suggesting a detailed evaluation of radial artery patency should be done before hospital discharge.

Keywords: radial artery occlusion, catheterization, trans-radial approach

Citation: Butt UM, Bakar MA, Iqbal MK, Shoukat S, Khan RSAT, Ali M. Frequency of Radial Artery Occlusion in Patients Undergoing Percutaneous Cardiac Catheterization by Radial Access. Pak Heart J. 2021;54(03):230-234. DOI: https://doi.org/10.47144/phj.v54i3.2146

\section{INTRODUCTION}

The gold standard technique for the diagnostic as well as therapeutic purpose in atherosclerotic coronary artery disease is coronary angiography. The various arterial accesses for coronary angiography include femoral, radial, brachial, ulnar, or axillary vessels. ${ }^{1}$

The most common site used for percutaneous coronary intervention is femoral artery. This approach is troubled with risk of puncture site bleeding, which deteriorates the outcome of the patient, despite easiness and simplicity of this approach ${ }^{2}$ In modern era alternative access through the radial artery is becoming more and more popular due to a substantial reduction of puncture site bleeding complication in comparison to femoral artery access. The recent ESC guidelines recommend radial access in ST-segment elevation myocardial infarction (STEMI) patients as a preferred approach in terms of reduction in primary outcomes like death, myocardial infarction and stroke. On top of that this approach provides comfort to the patient regarding mobility, short post catheterization stay at hospital and less financial burden on the patient.
But the main problem with transradial approach (TRA) is radial artery occlusion (RAO) after the procedure. ${ }^{2-4}$

RAO is the commonest complications of cardiac catheterization performed through this approach (incidence $0.8 \%-30 \%) .{ }^{5}$ In some other studies the overall incidence of RAO varies from $1.5 \%$ to $30.5 \%$ (average 5-12\%). ${ }^{6,7}$ One study showed that there were only $9.4 \%$ patients who has RAO after transradial catheterization. ${ }^{1}$ But another study showed that RAO was reported in $15.2 \%$ patients. $^{8}$ After transradial procedures, hemostasis is secured either with elastic bandage application or using dedicated graded radial pressure devices. Such devices are usually applied to maintain patent hemostasis where distal flow via radial artery is not hampered during the process of hemostasis due to just adequate amount of pressure applied. Such dedicated devices, despite being the current standard of care in developed countries, are still not being use in local centers due to cost and availability issues. Most of the published data regarding radial artery occlusion rates after cardiac 
catheterization comes from the centers where dedicated graded radial pressure devices are standard of care. With locally practiced elastic bandage application, the amount of pressure can be adjusted. Thus, RAO is not uncommon finding rendering radial artery not useable for any further catheterization. Local data does not exist in this regard and the international data is quite variable and that too is with dedicated devices.

We intend to carry out this study in order to assess RAO rates in our local practice where elastic bandage is used for hemostasis. In case of high RAO rates, use of dedicated devices may be advocated for better patient care. Therefore; the present study was planned to assess the frequency of radial artery occlusion (RAO) in patients undergoing percutaneous cardiac catheterization.

\section{METHODOLOGY}

A Descriptive cross sectional study was carried out at cardiology department Jinnah hospital, Lahore from April - October 2018. After approval of ethical review board of Allama Iqbal medical college, Lahore and informed consent from patients was obtained. Consecutive patients planned for percutaneous cardiac catheterization between $30-80$ years of either gender were selected. A sample size of 131 was calculated with $95 \%$ confidence level, 5\% margin of error and taking expected percentages of RAO i.e. 9.4\% undergoing cardiac catheterization. ${ }^{1}$ Patients with previous history of transradial cardiac catheterization, radial artery not suitable for catheterization on clinical assessment, creatinine $>1.3 \mathrm{mg} / \mathrm{dl}$, deranged liver function tests (ALT > $401 \mathrm{U}, \mathrm{AST}>401 \mathrm{U}$, Bilirubin > $1.5)$ or with history of vasculitis or peripheral arterial disease were excluded from the study. Percutaneous cardiac catheterization was performed through transradial approach (TRA) and post procedure patients were followed in the ward and after 24 hours, Allen's test was used for checking the patency of the radial artery. Color Doppler USG was performed in the patients with absent radial artery and RAO was confirmed. SPSS version 21 was used for data analysis. Mean \pm standard deviation was used for quantitative variables like age and BMI. Frequency and percentage were used for qualitative variables like gender and RAO. Then stratification of data for various parameters like age, gender and duration and type of intervention was done. Chi square test was applied to compare RAO in stratified groups. Statistically significant $\mathrm{P}$-value was $\leq 0.05$.

\section{RESULTS}

The mean age of the patients was $52.57 \pm 11.86$ years, $83(63.4 \%)$ were males and $48(36.6 \%)$ were observed to be female. The mean body mass index of these patients was calculated to be $30.09 \pm 2.57 \mathrm{~kg} / \mathrm{m}^{2}$ and among them $65(49.6 \%)$ were overweight and 66 $(51.4 \%)$ were obese with BMI $>30 \mathrm{~kg} / \mathrm{m}^{2}$. There were $77(58.8 \%)$ patients underwent diagnostic coronary angiography whereas $54(41.2 \%)$ patients had coronary angioplasty. Mean duration of the procedure (included coronary angioplasty, angiography and percutaneous coronary intervention through radial artery approach) was calculated to be $18.64 \pm 7$ minutes. Radial artery occlusion (RAO) was present in $52(39.7 \%)$ detected by negative reverse Allen's test and confirmed by no radial artery flow on color Doppler USG. While in remaining 79 (60.3\%) patient's radial artery patency was identified on Allen's test and confirmed by Doppler study (Table 1).

On comparison between age, gender, duration and type and duration of procedure; statistically insignificant difference was observed $(\mathrm{p} \leq 0.05)$ (Table 2).

Table 1: Demographic and Clinical Profile of subjects

\begin{tabular}{|c|c|c|}
\hline & Frequency & Percent \\
\hline Age (years) & \multicolumn{2}{|c|}{$52.56 \pm 11.8$} \\
\hline$\leq 45$ & 29 & 22.1 \\
\hline$>45$ & 102 & 77.9 \\
\hline \multicolumn{3}{|l|}{ Gender } \\
\hline Male & 83 & 63.4 \\
\hline Female & 48 & 36.6 \\
\hline BMI $\left(\mathrm{kg} / \mathrm{m}^{2}\right)$ & \multicolumn{2}{|c|}{$30.09 \pm 2.57$} \\
\hline Overweight & 65 & 49.6 \\
\hline Obese & 66 & 50.4 \\
\hline Duration of procedure (min) & \multicolumn{2}{|c|}{$18.64 \pm 7.67$} \\
\hline$\leq 15 \mathrm{~min}$ & 69 & 52.6 \\
\hline$>15 \mathrm{~min}$ & 62 & 47.1 \\
\hline \multicolumn{3}{|l|}{ Type of procedure } \\
\hline Angiography & 77 & 58.8 \\
\hline Angioplasty & 54 & 41.2 \\
\hline \multicolumn{3}{|l|}{ Radial artery occlusion } \\
\hline Yes & 52 & 39.7 \\
\hline No & 79 & 60.3 \\
\hline
\end{tabular}

Table 2: Radial artery occlusion and independent variables cross tabulation

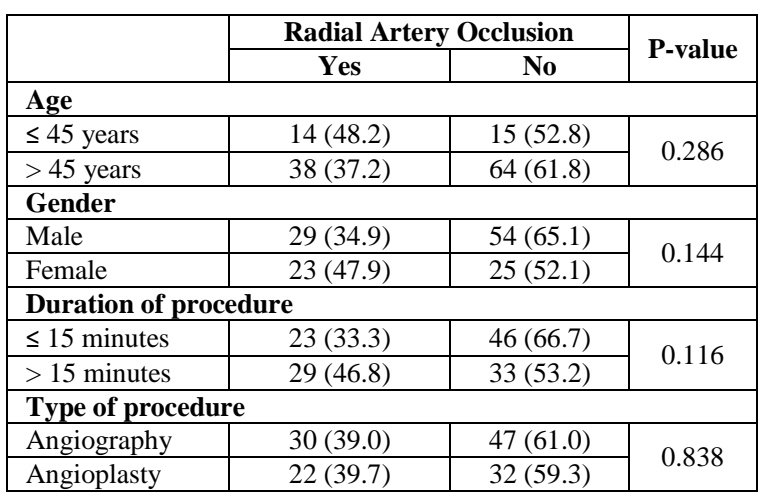




\section{DISCUSSION}

Radial artery occlusion (RAO) is the commonest complications of cardiac catheterization performed through transradial approach. In some studies the overall incidence of RAO varies from $1.5 \%$ to $30.5 \%$ (average 5-12\%). ${ }^{6}$ The incidence of RAO rests on various demographics, clinical and periprocedural factors, along with the time passed from the procedure to the radial artery examination for patency. This incidence further decreases by $50 \%$ if the radial artery is examined 30 days after cardiac catheterization, as compared to the instant checkup of the radial artery after the removal of pressure bandage removal. It reveals spontaneous radial artery recanalization. ${ }^{9,10}$

In our study it was intended to measure the frequency of radial artery occlusion through transradial approach in our population as local data is lacking and transradial access is less commonly approached regardless of its well-known safety and efficacy.

In our study the patients who underwent percutaneous cardiac catheterization via the transradial approach were present with the mean age of $52.56 \pm 11.86$ years which is similar to a study by Masud $\mathrm{F}$ et al. documenting mean age of $57.62 \pm 10.1$ years. ${ }^{11}$ Another study by Chowdhury MZ reported the mean age of patients $53.5 \pm 9.7$ years (range: $31-75$ years) which is similar but, in this study, when data was categorized in the groups it was seen that the most of the patients had age more than 50 but statistically insignificant difference was observed among age groups. In contrast to our results aforementioned studies reported age as a prognosticator of RAO, with elderly patients (above 60 years) having higher frequency of RAO. Similarly, $63.8 \%$ with age $>50$ years were declared to be having RAO by Chowdhury. ${ }^{12}$ Male into female percentage in our study was perceived to $63.4 \%$ versus $36.6 \%$ which is in line with the literature showed two thirds (66.7\%) were male by Chowdhury. Another study reported comparable results with respect to gender (male 68.8\% and female $32.2 \%$ ).

All patients were overweight and obese in our results who present for PCI whereas the normal weight patients $(47.8 \%)$ were also foreseen in previous studies incidence of overweight and obese patients was $43.5 \%$ and $8.7 \%$ respectively. Incidence of hypertension, diabetes mellitus (DM), dyslipidemia and smoking were $80 \%, 65 \%, 57 \%$ and $38 \%$ respectively. ${ }^{12}$ A Study by Tuncez had inverse results with respect to high percentage of female gender
(56.6\%) and Hypertension (81.1\%) DM (34.9\%) Hyperlipidemia (85\%) Smoking (47.2\%). ${ }^{1}$

Mean interval of Cine-fluoroscopy for coronary angiography was $2.75 \pm 1.5 \mathrm{~min}$ and percutaneous coronary intervention (PCI) $8.29 \pm 5.1$ minutes. ${ }^{1}$ These results are in accordance to previous data. Whereas in our study duration of coronary angiography by radial artery is 18.22 minutes and PCI 19.24 minutes.

The frequency of RAO was found to be $39.7 \%$ in our study and in another study, this was $7.1 \%{ }^{11}$ which is less than in comparison to a large study by Tuncez et al. $(9.4 \%){ }^{1}{ }^{1}$ In another study by Indian Sreevasta et al. it was $13.1 \% .^{13}$ These findings are in accordance to current meta-analysis published by Rashid et al. where RAO incidence was found to be $7.7 \%$ in first 24 hours and $5.8 \%$ after 30 days of cardiac catherization. ${ }^{14}$

In contrast to above mentioned results related to incidence of RAO, study by Chowdhury done on 69 patients undergoing cardiac catheterization, only one old age patient $(1.45 \%)$ had RAO on follow-up at third month which is quite less than documented (up to $18 \%$ ) by some other studies. ${ }^{1-7}$ Although this patient was asymptomatic despite ischemic hand detected by no radial artery flow on Doppler ultrasound (USG), which could be explained by the presence of collaterals. Therefore, Kiemeneij recommended that radial approach for cardiac catheterization should be selected only in those patients with good ulnar and palmar arch blood flow. ${ }^{15}$ The patency of these vessels can be checked by the Allen's test before starting the procedure but gold standard methods are color doppler USG and plethysmography. ${ }^{12}$

Sinha et al. ${ }^{16}$ study 1945 consecutive patients undergone transradial catheterization demonstrated that RAO was found in 339 (174\%) patients through color doppler USG on day 1, although pulse was still palpable on examination in 115 (34\%) of these patients. While 30-day data showed RAO was found in $221(11.4 \%)$ patients and $114(52 \%)$ patients had palpable pulse. Surprisingly, 118 (34.8\%) of 339 patients having RAO showed spontaneous recanalization of the radial artery on doppler USG. Further follow up on 180 days, there was reduction in RAO to $99(5.1 \%)$ and palpable radial artery in 68 (69\%) patients was found which indicated more spontaneous recanalization. ${ }^{16}$

In our study there was significant reduction in RAO at 30 day by compressing ipsilateral ulnar artery prophylactically during radial artery compression for hemostasis after catheterization through radial approach. Rather RAO was 
considerably decreased on all the follow ups by this prophylactic compression. In the current era cardiac catheterization through radial approach becoming first choice all over the world but with factors like operators being at different level learning curve, increasing number of cardiac patients undergoing catheterization and complex nature of the procedure, measures should be taken to prevent RAO for future use of this safe approach in patients with recurrent ischemia requiring repeated angiograms. The incidence of RAO is lower in those patients who has palpable radial artery while compression of artery for hemostasis. ${ }^{4}$

When data was stratified with respect to effect modifiers it was noted that among age, gender, duration of procedure or type of intervention; statistically insignificant difference was observed among the radial artery occlusion and these variables. In the previous data, there was significant variation in RAO frequency in stratification of data for gender. A study by Masud $\mathrm{F}$ et al. conducted on 141 patients, RAO was found in $10(7.1 \%)$ patients and out of these $6(60 \%)$ were females and $4(40 \%)$ were males. ${ }^{11}$ Similar trends were seen in studies done by Tuncez et al. (80\% female patients with RAO) and Rashid et al. (66.7\% female patients with RAO). This gender difference is most probably due to main factor of small ration of radial artery to arterial sheath seen in females. ${ }^{14}$ A local study demonstrated that higher incidence of RAO was seen in patients undergoing PCI (9) as compared to those undergoing angiogram (1) and these results were in accordance to study by Tuncez et al. In those 10 patients with RAO there was difference of procedure time $(<30 \mathrm{~min}$ in $1,<60 \mathrm{~min}$ in 7 and $>1$-hour in 2 patients). But the effects of procedure type and duration on RAO were not statistically significant (p-value $=0.195$ and 3.55). ${ }^{11}$ Sinha study results provided multivariate analysis, and prove that various predictors of RAO include female gender, DM, low BMI, small radial artery $(\leq 2.2 \mathrm{~mm})$ and small radial artery to sheath ratio $<1 .{ }^{16}$

The limitation in our study was that best time point at which to assess RAO is unknown; however, previous studies demonstrated that the incidence of RAO is reduced over time compared with day 1 , and if the artery was patent initially, it usually does not occlude later. ${ }^{7,8,16}$ There is variability in different studies in the time at which RAO was assessed. We chose to assess $\mathrm{RAO}$ on the day of the procedure because the majority of our patients were discharged the same day and resided at large distances from the hospital. At this time, the incidence of RAO is highest. Patients who resided closer were asked to come back for follow-up, and indeed, we found that the incidence of RAO was reduced after 1 week compared with the day of the procedure.

\section{CONCLUSION}

In our study a considerable number of patients were observed with radial artery occlusion with trans radial approach thought statistically insignificant difference was noted among all ages, gender or type of intervention suggesting a detailed evaluation of radial artery patency should be done before hospital discharge and to avoid this potential complication multidirectional efforts are required to expand the operator's skills, use of highquality equipment, acceptable anticoagulation and particularly to improve the method of attaining hemostasis. Therefore, while proceeding through transradial approach during interventions, a detailed evaluation of radial artery patency should be done before hospital discharge.

\section{AUTHORS' CONTRIBUTION}

$\mathrm{UMB}$ conceived the idea, designed the study and analysed the data. MAB and SS did data collection. MKI and RSATK did the manuscript writing. MA did review and final approval of manuscript. All the authors contributed significantly to the research that resulted in the submitted manuscript.

Conflict of interest: Authors declared no conflict of interest.

\section{REFERENCES}

1. Avdikos G, Karatasakis A, Tsoumeleas A, Lazaris E, Ziakas A, Koutouzis M. Radial artery occlusion after transradial coronary catheterization. Cardiovasc Diagn Ther. 2017;7(3):305-16.

2. Bernat I, Aminian A, Pancholy S, Mamas M, Gaudino M, Nolan $\mathrm{J}$, et al. Best Practices for the Prevention of Radial Artery Occlusion After Transradial Diagnostic Angiography and Intervention: An International Consensus Paper. JACC Cardiovasc Interv. 2019;12(22):2235-46.

3. Slawin J, Kubler P, Sczezepanski A, Piatek , Stepkowski M, Reczuch K. Radial artery occlusion after percutaneous coronary interventions an underestimated issue. Postepy Kardiol Interwencyjnej. 2013;9:353-61.

4. Pancholy SB, Bernat I, Bertrand OF, Patel TM. Prevention of Radial Artery Occlusion After Transradial Catheterization: The PROPHET-II Randomized Trial. JACC Cardiovasc Interv. 2016;9(19):1992-99.

5. Wagener JF, Rao SV. Radial artery occlusion after transradial approach to cardiac catherization. Curr Atheroscler Rep. 2015; $17: 1-8$

6. Bertrand OF, Rao SV, Pancholy S, Jolly SS, Rodes-Caban J, Larose E, et al. Transradial approach for coronary angiography and interventions: results of the first international transradial practice survey. J Am Coll Cardiol Cardiovasc Interven. 2010;3:1022-31.

7. Lavi S, Cheema A, Yadegari A, Israeli Z, Levi Y, Wall S, et al. Randomized trial of compression duration after transradial cardiac catheterization and intervention. $\mathrm{J}$ Am Heart Assoc. 2017;6(2):e005029.

8. Garg N, Madan B.K, Khanna R, Sinha A, Kapoor A, Tewari S, et al. Incidence and Predictors of Radial Artery Occlusion After 
Transradial Coronary Angioplasty: Doppler-Guided Follow-up Study. J Inv Cardio. 2015;27(2):106-12.

9. Ali S, Abdullah MS, Abdelrahman K, Ali A, Faisal F, Ali A. Total Radial Artery Occlusion Following Transradial Access: Complete Recanalization via the Anatomical Snuffbox. Methodist Debakey Cardiovasc J. 2020;16(4):314-7.

10. Koutouzis M, Maniotis C, Avdikos G. Prevention of Radial Artery Occlusion After Transradial Catheterization. JACC Cardiovasc Interv. 2017;10(1):103.

11. Masud F, Hassan Y. Radial artery occlusion- a burden or a challenge? Pak Heart J. 2017;50(01):14-8.

12. Chowdhury MZ, Kabir CMS, Nasrin S, Gomes HI, Hakim E, Khan SR, et al. Radial Artery Patency after Trans-radial Cardiac Catheterization in a Bangladeshi Population. Uni Heart J. 2014; 10(2):66-72.

13. Tewari S, Sharma N, Kapoor A, Syal SK, Kumar S, Garg N, et al. Comparison of transradial and transfemoral artery approach for percutaneous coronary angiography and angioplasty: a retrospective sevenyear experience from a north Indian center. Indian Heart J. 2013;65(4):378-87.

14. Rashid M, kwok CH, Pancholy S, Chugh S, Sasko A, Ratib K, et al. Radial artery occlusion after transradial Interventions: a systemic review and meta-analysis. J Am Heart Assoc. 2016;5(1):26-86.

15. Hahalis G, Aznaouridis K, Tsigkas G, Davlouros P, Xanthopoulou I, Koutsogiannis N, et al. Radial Artery and Ulnar Artery Occlusions Following Coronary Procedures and the Impact of Anticoagulation: ARTEMIS (Radial and Ulnar ARTEry Occlusion Meta-AnalysIS) Systematic Review and MetaAnalysis. J Am Heart Assoc. 2017;6(8):e005430.

16. Sinha SK, Jha MJ, Mishra V, Thakur R, Goel A, Kumar AA. Radial Artery Occlusion - Incidence, Predictors and Long-term outcome after TRAnsradial Catheterization: clinico-Doppler ultrasound-based study (RAIL-TRAC study). J Acta Cardiologica 2017;72(3):318-27.

\section{Address for Correspondence:}

Dr. Usman Mahmood Butt, Department of Cardiology, Jinnah Hospital, Lahore, Pakistan.

Email: usman_sw@hotmail.com 